\title{
Protocols for multi-step thermoplastic processing of metallic glasses
}

\author{
Punnathat Bordeenithikasem ${ }^{\mathrm{a}}$, Sungwoo Sohn ${ }^{\mathrm{a}}$, Ze Liu ${ }^{\mathrm{a}}$, Jan Schroers ${ }^{\mathrm{a}, *}$ \\ ${ }^{a}$ Department of Mechanical Engineering and Materials Science, Yale University, New Haven, \\ CT 06511, USA \\ *Corresponding author: \\ Email: jan.schroers@yale.edu \\ Postal Address: 15 Prospect St., Becton Center 217, New Haven, CT 06511, USA
}

\begin{abstract}
Temperature profiles of multi-step thermoplastic forming of bulk metallic glasses were simulated by isothermal annealing at multiple temperatures and sequences. For a single annealing temperature, the time to crystallize is additive. When the sample is first annealed at a higher temperature and quenched to a lower temperature, time till crystallization is gained, and vice versa. These findings can be explained by the temperature dependence of nucleation and growth rates, which suggests the maximum nucleation temperature is below thermoplastic forming temperatures.
\end{abstract}

\section{MANUSCRIPT}

Unique among metals, bulk metallic glasses (BMGs) exhibit a supercooled liquid region (SCLR), the temperature region where the glass relaxes into a supercooled liquid before it eventually crystallizes. In this region, bounded by the glass transition temperature $\left(T_{\mathrm{g}}\right)$ and the crystallization temperature $\left(T_{\mathrm{x}}\right)$, viscosities down to $\sim 10^{6} \mathrm{~Pa}$ s can be obtained on experimentally convenient time scales [1-5]. This softening behavior has been explored for thermoplastic forming (TPF). TPF of BMGs has produced parts on length scales spanning over ten orders of magnitude with unprecedented precision [6-15] and some previously unattainable shapes [16-23]. 
The main challenge in TPF of BMGs is to avoid crystallization during forming. The metastable nature of the glass phase implies a thermodynamic driving force for crystallization, which increases in magnitude with decreasing temperature below the liquidus temperature $\left(T_{\mathrm{L}}\right)$. Simultaneously, the kinetics for crystallization is reduced with decreasing temperature. Consequently, when the BMG is heated from ambient temperature into the SCLR, the kinetics for crystallization is dramatically enhanced. Crystallization, even for small volume fractions, dramatically deteriorates the attractive mechanical properties of BMGs [24-28] and terminates the deformation process [23, 29-31]. The formability of a BMG is controlled by the available processing time before crystallization and the inverse of viscosity [32]. Studies on temperature dependence of the formability have revealed that formability increases monotonically with temperature [33]. Thus, selecting the highest processing temperature, such that crystallization can still be avoided will ensure the highest formability. This temperature dependence of the formability has motivated TPF processing methods on very short time scales, permitting high temperatures and formabilities [34, 35].

For the fabrication of complex geometries, a combination of TPF processes or steps is often required. Examples include TPF-based blow-molding of TPF-based rolled or compressed BMG sheets [22, 36, 37] and BMG hierarchal structures [38]. During such multi-step TPF processing, the BMG-forming alloy is heated into the SCLR and cooled below $T_{\mathrm{g}}$ for multiple times. However, an understanding on how prior TPF steps affect subsequent TPF steps, specifically in terms of the available processing time and crystallization kinetics, is missing. Here, we determine how isothermal anneals at one temperature affect crystallization at another temperature.

We use a differential scanning calorimeter (DSC) for isothermal annealing to simulate typical TPF thermal profiles. As example BMG systems, we use $\mathrm{Zr}_{44} \mathrm{Ti}_{11} \mathrm{Cu}_{10} \mathrm{Ni}_{10} \mathrm{Be}_{25} \mathrm{BMG}$ (Zr-BMG) and $\mathrm{Pd}_{43} \mathrm{Cu}_{27} \mathrm{Ni}_{10} \mathrm{P}_{20}$ BMG (Pd-BMG). Both alloys have been broadly used for 
TPF-based processing $[6,16,22,39-42]$. The characteristic temperatures, $T_{\mathrm{g}}$ and $T_{\mathrm{x}}$, of the BMGs were first measured using DSC heating at $20 \mathrm{~K} / \mathrm{min}$ to be $350{ }^{\circ} \mathrm{C}$ and $481{ }^{\circ} \mathrm{C}$, respectively for $\mathrm{Zr}-\mathrm{BMG}$, and $308^{\circ} \mathrm{C}$ and $412^{\circ} \mathrm{C}$, respectively for Pd-BMG. Then, the onset time of crystallization of the as-cast alloy, $t_{\mathrm{x}, \text { as-cast }}(T)$, the maximum available processing time at temperature $T$, was measured for all relevant temperatures for both alloys.

We first simulated multi-step TPF profiles at a single temperature (Figure 1). Here, Zr-BMG samples were placed in a DSC and heated from room temperature to $460{ }^{\circ} \mathrm{C}$ at a rate of $150 \mathrm{~K} / \mathrm{min}$ and then held isothermally for 1,2 , or $3 \mathrm{~min}$. Subsequently, the sample was quenched at $150 \mathrm{~K} / \mathrm{min}$ to $300{ }^{\circ} \mathrm{C}$ and held isothermally for $2 \mathrm{~min}$ to equilibrate. The sample was reheated to $460{ }^{\circ} \mathrm{C}$ at $150 \mathrm{~K} / \mathrm{min}$ and held isothermally until crystallization is observed (Figure 1). For each sample, the sum of the amount of time that the sample was first annealed at $460{ }^{\circ} \mathrm{C}(1,2$, or $3 \mathrm{~min})$ and the remaining onset time of crystallization measured at the second annealing at $460{ }^{\circ} \mathrm{C}$ is equal to $t_{\mathrm{x}, \text { as-cast }}\left(460{ }^{\circ} \mathrm{C}\right)$. We carried out similar experiments at other temperatures and found that the time to crystallization at a single temperature is an additively conserved quantity.

In order to quantify the effect of multiple processing temperatures on subsequent processing steps, various temperature combinations were considered (Figure 2). To compare the effects of multi-step annealing, each sample was heated at $150 \mathrm{~K} / \mathrm{min}$ from ambient temperature to a temperature $\left(T_{1}\right)$ for $\frac{t_{x, a s-c a s t}\left(T_{1}\right)}{2}$. Subsequently, the sample is heated or cooled at $150 \mathrm{~K} / \mathrm{min}$ to a different temperature $\left(T_{2}\right)$, where it is held isothermally and the onset time of crystallization, $t_{\mathrm{x}, \text { remaining }}$, is recorded. The schematic of the temperature profile for this protocol is illustrated in Figure 2(a). This protocol was carried out for Zr-BMG with $T_{1}$ 's of $370{ }^{\circ} \mathrm{C}, 400{ }^{\circ} \mathrm{C}, 430{ }^{\circ} \mathrm{C}, 460{ }^{\circ} \mathrm{C}$, and $480{ }^{\circ} \mathrm{C}$ which were followed by $T_{2}$ 's of $400{ }^{\circ} \mathrm{C}$, $430{ }^{\circ} \mathrm{C}$, and $460{ }^{\circ} \mathrm{C}$. For Pd-BMG, the protocol was carried out with $T_{1}$ 's of $350{ }^{\circ} \mathrm{C}, 370{ }^{\circ} \mathrm{C}$, 
and $390{ }^{\circ} \mathrm{C}$ which were followed by a $T_{2}$ of $370{ }^{\circ} \mathrm{C}$. The ratio of the $t_{\mathrm{x}, \text { remaining }}$ to $t_{\mathrm{x}, \text { as-cast }}\left(T_{2}\right)$ is plotted against $T_{1}$ in Figure 2(b) and (c).

For multi-step processing temperature profiles, where the two steps are carried out at

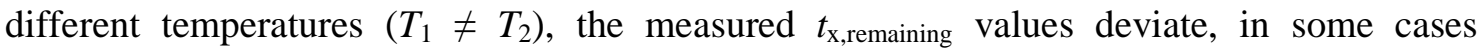
extremely, from $\frac{t_{x, a s-c a s t}\left(T_{2}\right)}{2}$. When the measured $t_{\mathrm{x}, \text { remaining }}$ exceeds $\frac{t_{x, a s-\text { cast }}\left(T_{2}\right)}{2}$, the sample appears to "gain" time before crystallization. When the measured $t_{\mathrm{x} \text {,remaining }}$ is below $\frac{t_{x, a s-\text { cast }}\left(T_{2}\right)}{2}$, the sample appears to "lose" time before crystallization. The $t_{\mathrm{x}, \text { remaining }}$ to $t_{\mathrm{x}, \mathrm{as}-}$ cast $\left(T_{2}\right)$ ratio monotonically increases with $T_{1}$ at constant $T_{2}$, and becomes $50 \%$ when $T_{1}$ is equal to $T_{2}$. Therefore, when $T_{1}$ is greater than $T_{2}$, the sample gains time before crystallization, and vice versa. The magnitude of the deviation from the $50 \%$ value also scales with the difference between $T_{1}$ and $T_{2}$. This is observed for both $\mathrm{Zr-BMG}$ and Pd-

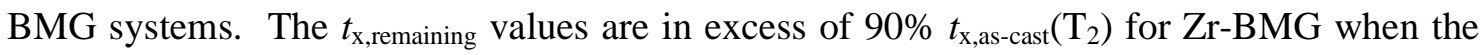
samples were annealed at $T_{1}$ of $460{ }^{\circ} \mathrm{C}$ and $480{ }^{\circ} \mathrm{C}$ followed by a quench to $T_{2}$ of $400{ }^{\circ} \mathrm{C}$ or $430{ }^{\circ} \mathrm{C}$. In the most extreme cases, e.g. $T_{1}=480{ }^{\circ} \mathrm{C}$ and $T_{2}=430{ }^{\circ} \mathrm{C}$, annealing at $T_{1}$ has essentially no effect on subsequent annealing at $T_{2}$. Similarly, when Pd-BMG samples were annealed at $T_{1}$ of $390{ }^{\circ} \mathrm{C}$ followed by a quench to $T_{2}$ of $370{ }^{\circ} \mathrm{C}, t_{\mathrm{x} \text {,remaining }}$ was measured to be $83 \%$ of $t_{\mathrm{x}, \text { as-cast }}\left(370{ }^{\circ} \mathrm{C}\right)$. We observed the highest reduction in time before crystallization for Zr-BMG when $T_{1}$ was $370{ }^{\circ} \mathrm{C}$ followed by heating to $T_{2}$ of $430{ }^{\circ} \mathrm{C}$; the $t_{\mathrm{x}, \text { remaining }}$ is only $25 \%$ of $t_{\mathrm{x}, \text { as-cast }}\left(430{ }^{\circ} \mathrm{C}\right)$. $\quad$ Likewise, when Pd-BMG samples were annealed at $T_{1}$ of $350{ }^{\circ} \mathrm{C}$ followed by heating to $T_{2}$ of $370{ }^{\circ} \mathrm{C}$, the $t_{\mathrm{x}, \text { remaining }}$ is $23 \%$ of $t_{\mathrm{x} \text {,as-cast }}\left(370{ }^{\circ} \mathrm{C}\right)$.

Due to the higher activation energy required for nucleation than for growth, we assume a qualitative temperature dependence of the nucleation and growth rate, depicted in Figure 3, with the maximum nucleation rate at a lower temperature than the maximum growth rate. Since nucleation and growth rates are constant for the final isothermal DSC 
scans at the same $T_{2}$, the difference in thermal behavior of the samples of different thermal histories is attributable to the difference in nuclei density that was generated in the prior annealing step at $T_{1}$. The fact that $t_{\mathrm{x}, \text { remaining }}$ to $t_{\mathrm{x}, \text { as-cast }}\left(T_{2}\right)$ ratio monotonically increases with $T_{1}$ at constant $T_{2}$ suggests that the nucleation rate monotonically decreases with increasing temperature for the experimental temperature range. This finding suggests the maximum nucleation rate is at a temperature lower than the considered temperature range.

To further investigate the location of temperature of the maximum nucleation rate on the temperature axis, $\mathrm{Zr}$-BMG samples were annealed using the protocol described above (Figure 2(a)) with $T_{1}$ 's of $370{ }^{\circ} \mathrm{C}, 400{ }^{\circ} \mathrm{C}, 430{ }^{\circ} \mathrm{C}, 460{ }^{\circ} \mathrm{C}$, and $480{ }^{\circ} \mathrm{C}$ followed by $T_{2}$ of $480{ }^{\circ} \mathrm{C}$. Similarly, Pd-BMG samples were annealed with $T_{1}$ 's of 350,370 , and $390{ }^{\circ} \mathrm{C}$ followed by $T_{2}$ of $390{ }^{\circ} \mathrm{C}$. We used the full width at half maximum (FWHM) of the crystallization peak as an inverse measure of the crystallization rate. The FWHM values of the exothermic peak were measured and compiled in Figure 4. Since FWHM was measured for a DSC thermogram acquired from isothermal annealing at the same $T_{2}$, the growth rate for the entire data series is constant. Therefore, the difference in FWHM values and thus crystallization kinetics correlate with nuclei density formed during the prior annealing step at $T_{1}$. Hence, FWHM values provide information about the nucleation rate at $T_{1}$; the lower the FWHM, the higher the nucleation rate. FWHM values increase for increasing $T_{1}$, suggesting that the temperature of maximum nucleation rate is below the experimental temperature range. This finding is surprising and different from results obtained by fitting crystallization kinetics with classical nucleation behavior, which suggests that the maximum of the nucleation rates occur at much higher temperatures, in the vicinity of the nose of the timetemperature-transformation diagram [1, 3, 43, 44], for both Zr-BMG and Pd-BMG systems.

In summary, we found that when BMG samples are annealed at a single temperature $\left(T_{1}=T_{2}\right)$ the time till the onset of crystallization is additive. However, for a multi-step anneal 
at various temperatures $\left(T_{1} \neq T_{2}\right)$, the crystallization time can drastically deviate from an additive behavior. When BMG samples were first annealed at a temperature in the SCLR and subsequently annealed at a lower temperature in the SCLR $\left(T_{1}>T_{2}\right)$, the time till the onset of crystallization is gained. In contrast, when BMG samples were first annealed at temperature in the SCLR and subsequently annealed at a higher temperature in the SCLR $\left(T_{1}<T_{2}\right)$, the time till the onset of crystallization is reduced. This non-additive behavior can be explained with the temperature dependence of the nucleation and growth rates and their absolute values. The findings have ramifications for designing multi-step TPF processing. When possible, a processing protocol should be chosen with the initial step at a higher temperature before a lower temperature process to ensure the longest processing time before crystallization, hence maximizing the formability. Technologically, the revealed multi-step protocols allow for effective processing where higher formability than from a simple additive process can be achieved.

\section{ACKNOWLEDGEMENT}

The work was funded by Department of Energy through the Office of Basic Energy Sciences (\#DE SC0004889). The authors would like to thank Hannah Mae Robinson for her help in sample preparation.

(a)

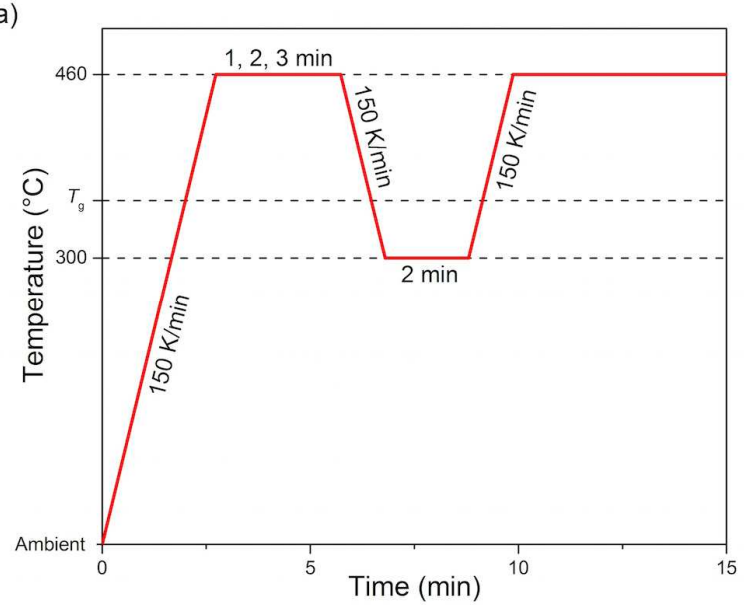

(b)

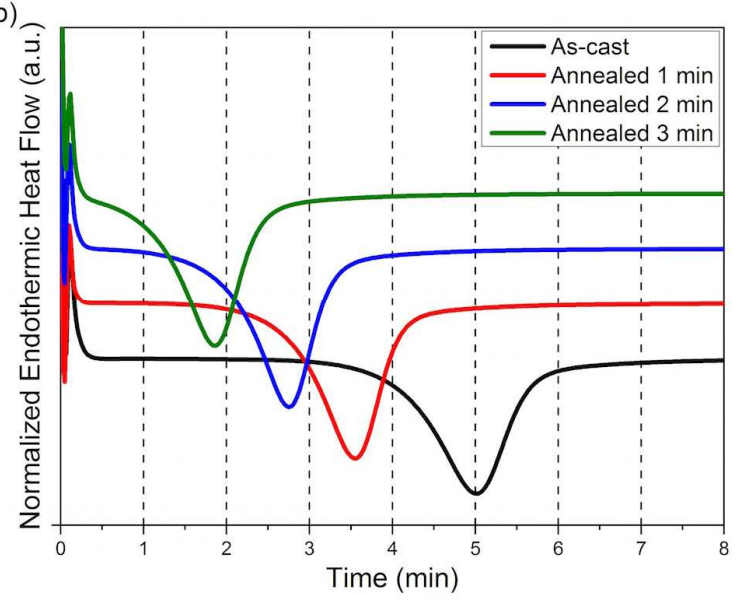


Figure 1. (a) Schematic of the DSC temperature profile used to simulate multi-step TPF at one temperature, $460{ }^{\circ} \mathrm{C}$. (b) DSC thermograms of the final isothermal scan of Zr-BMG samples that have been first annealed at $460{ }^{\circ} \mathrm{C}$ for 1,2 , or $3 \mathrm{~min}$ in comparison to the as-cast sample.
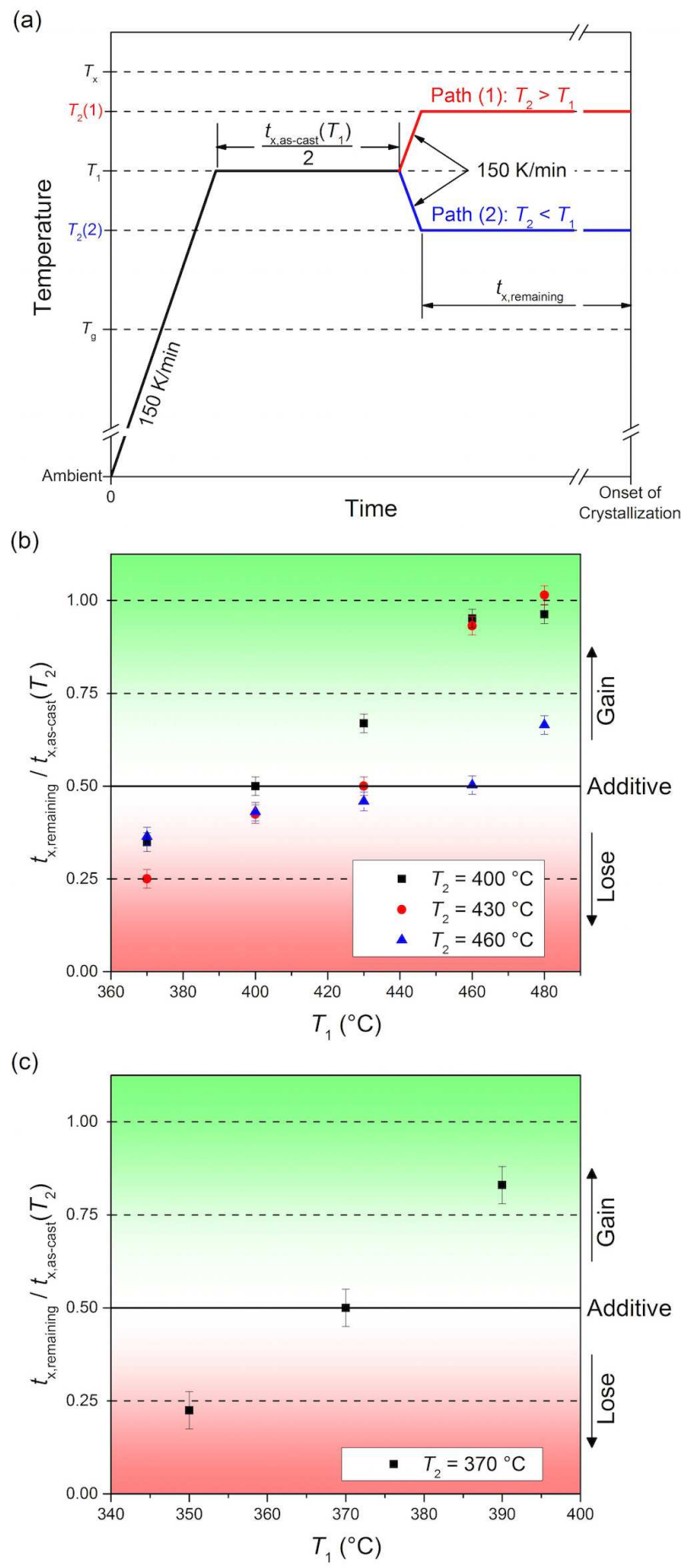

60

61 
Figure 2. (a) Schematic of the DSC temperature profile used to study the effect of multiple temperatures on subsequent processing steps. The sample was first heated from ambient temperature to $T_{1}$ at $150 \mathrm{~K} / \mathrm{min}$ where it is annealed isothermally for a time of $\frac{t_{x, a s-\text { cast }}\left(T_{1}\right)}{2}$. The sample is then heated (Path (1)) or cooled (Path (2)) to a different temperature, $T_{2}$. The time till the onset of crystallization at $T_{2}$ is $t_{\mathrm{x}, \text { remaining. }}$ The ratio of $t_{\mathrm{x}, \text { remaining }}$ to $t_{\mathrm{x}, \mathrm{as}-\mathrm{cast}}\left(T_{2}\right)$ is plotted against $T_{1}$ for (b) Zr-BMG and (c) Pd-BMG for various $T_{1}$ 's and $T_{2}$ 's. When the $t_{\mathrm{x}, \text { remaining }}$ to $t_{\mathrm{x}, \text { as-cast }}\left(T_{2}\right)$ ratio is at $50 \%$, the time till onset of crystallization is additive. Below $50 \%$, the time till crystallization is lost. Above $50 \%$, the time till onset of crystallization is gained.

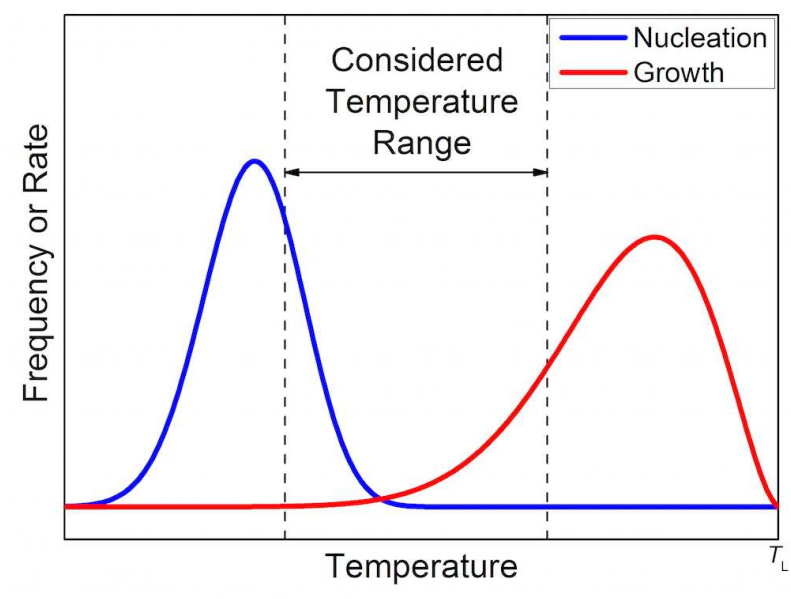

Figure 3. Schematic of the steady-state nucleation and growth rate curves as a function of temperature. 
(a)

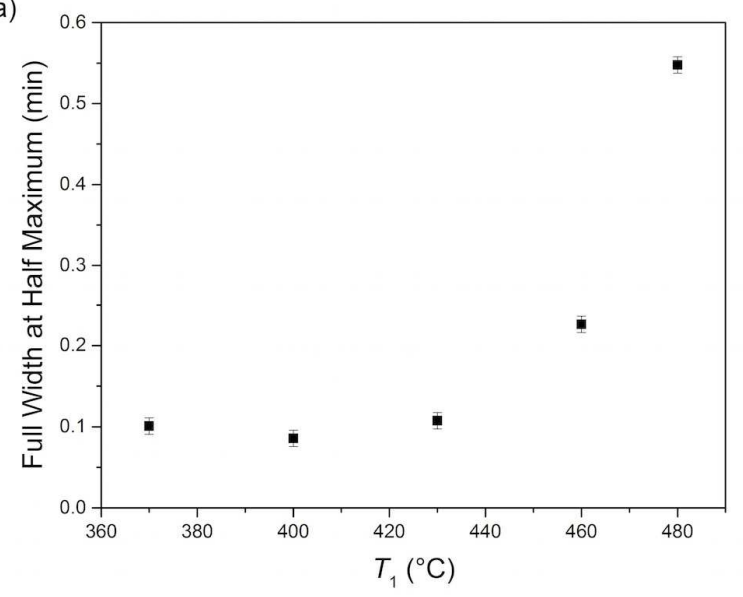

(b)

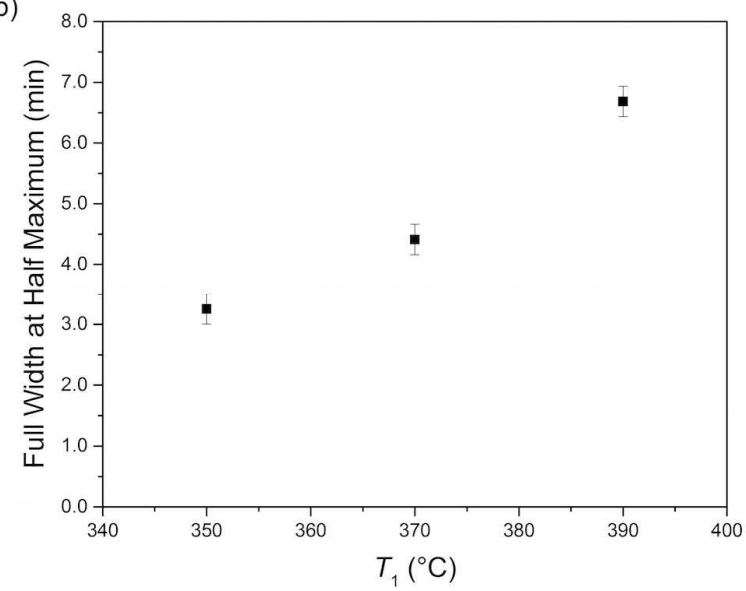

Figure 4. FWHM of the crystallization event on the DSC thermograms of (a) Zr-BMG and

(b) Pd-BMG samples that were subjected to a thermal profile described by Figure 2(a) with multiple $T_{1}$ 's and $T_{2}$ of $480{ }^{\circ} \mathrm{C}$ for $\mathrm{Zr}-\mathrm{BMG}$ and $390{ }^{\circ} \mathrm{C}$ for Pd-BMG.

\section{REFERENCES}

[1] R. Busch, J. Schroers, W.H. Wang, MRS Bull., 32 (2007) 620-623.

[2] W.L. Johnson, M.D. Demetriou, J.S. Harmon, M.L. Lind, K. Samwer, MRS Bull., 32 (2007) 644-650.

[3] G. Duan, A. Wiest, M.L. Lind, J. Li, W.K. Rhim, W.L. Johnson, Adv. Mater., 19 (2007) 4272-4275.

[4] A. Takeuchi, H. Kato, A. Inoue, Intermetallics, 18 (2010) 406-411.

[5] T. Yamasaki, M. Yamada, T. Mori, Y. Kikuchi, A. Inoue, D.H. Kim, Mater. Sci. Forum, 654-656 (2010) 1045-1049.

[6] J. Schroers, Adv. Mater., 22 (2010) 1566-1597.

[7] J. Schroers, Phys. Today, 66 (2013) 32-37.

[8] M. Kanik, P. Bordeenithikasem, G. Kumar, E. Kinser, J. Schroers, Appl. Phys. Lett., 105 (2014) 131911.

[9] K.S. Nakayama, Y. Yokoyama, T. Ono, M.W. Chen, K. Akiyama, T. Sakurai, A. Inoue, Adv. Mater., 22 (2010) 872-875.

[10] K.S. Nakayama, Y. Yokoyama, T. Wada, N. Chen, A. Inoue, Nano Lett., 12 (2012) 2404-2407.

[11] J.P. Chu, H. Wijaya, C.W. Wu, T.R. Tsai, C.S. Wei, T.G. Nieh, J. Wadsworth, Appl. Phys. Lett., 90 (2007) 034101.

[12] N. Chen, H.A. Yang, A. Caron, P.C. Chen, Y.C. Lin, D.V. Louzguine-Luzgin, K.F. Yao, M. Esashi, A. Inoue, J. Mater. Sci., 46 (2011) 2091-2096.

[13] X. Liu, Y. Shao, J.-F. Li, N. Chen, K.-F. Yao, J. Alloys Compd., 605 (2014) 7-11. [14] X. Liu, Y. Shao, S.-Y. Lu, K.-F. Yao, J. Polym. Sci., Part B: Polym. Phys., 53 (2015) 463-467.

[15] C. Yen Chen, T. Tsong Ru, P.C. Jinn, S. Hsuan, S.C.J. Jason, K. Hidemi, Applied Physics Express, 5 (2012) 012201.

[16] Y. Saotome, K. Itoh, T. Zhang, A. Inoue, Scripta Mater., 44 (2001) 1541-1545.

[17] Y. Saotome, K. Imai, S. Shioda, S. Shimizu, T. Zhang, A. Inoue, Intermetallics, 10 (2002) 1241-1247. 
[18] J. Hee-Won, S. Hata, A. Shimokohbe, J. Microelectromech. Syst., 12 (2003) 42-52.

[19] A. Inoue, A. Takeuchi, Acta Mater., 59 (2011) 2243-2267.

[20] J.A. Bardt, G.R. Bourne, T.L. Schmitz, J.C. Ziegert, W. Gregory Sawyer, J. Mater. Res., 22 (2007) 339-343.

[21] J. Schroers, B. Lohwongwatana, W.L. Johnson, A. Peker, Mater. Sci. Eng., A, 449-451 (2007) 235-238.

[22] J. Schroers, T.M. Hodges, G. Kumar, H. Raman, A.J. Barnes, Q. Pham, T.A. Waniuk, Mater. Today, 14 (2011) 14-19.

[23] J. Schroers, JOM, 57 (2005) 35-39.

[24] C.J. Gilbert, R.O. Ritchie, W.L. Johnson, Appl. Phys. Lett., 71 (1997) 476-478.

[25] N. Nagendra, U. Ramamurty, T.T. Goh, Y. Li, Acta Mater., 48 (2000) 2603-2615.

[26] M. Yan, J.F. Sun, J. Shen, J. Alloys Compd., 381 (2004) 86-90.

[27] K.S. Lee, J. Eckert, H.-J. Jun, Y.W. Chang, J. Mater. Res., 22 (2007) 1849-1858.

[28] G. Kumar, D. Rector, R.D. Conner, J. Schroers, Acta Mater., 57 (2009) 3572-3583.

[29] G. Wang, J. Shen, J.F. Sun, Y.J. Huang, J. Zou, Z.P. Lu, Z.H. Stachurski, B.D. Zhou, J.

Non-Cryst. Solids, 351 (2005) 209-217.

[30] S.V. Ketov, A. Inoue, H. Kato, D.V. Louzguine-Luzgin, Scripta Mater., 68 (2013) 219222.

[31] E.S. Park, J.H. Na, D.H. Kim, J. Appl. Phys., 108 (2010) 053515.

[32] J. Schroers, Acta Mater., 56 (2008) 471-478.

[33] E. Bryn Pitt, G. Kumar, J. Schroers, J. Appl. Phys., 110 (2011) 043518.

[34] Y. Saotome, Y. Noguchi, T. Zhang, A. Inoue, Mater. Sci. Eng., A, 375-377 (2004) 389393.

[35] W.L. Johnson, G. Kaltenboeck, M.D. Demetriou, J.P. Schramm, X. Liu, K. Samwer, C.P. Kim, D.C. Hofmann, Science, 332 (2011) 828-833.

[36] B. Sarac, G. Kumar, T. Hodges, S. Ding, A. Desai, J. Schroers, J. Microelectromech. Syst., 20 (2011) 28-36.

[37] M. Kanik, P. Bordeenithikasem, D. Kim, N. Selden, A. Desai, R. M'Closkey, J. Schroers, J. Microelectromech. Syst., 24 (2015) 19-28.

[38] M. Hasan, J. Schroers, G. Kumar, Nano Lett., 15 (2015) 963-968.

[39] D.L. Henann, V. Srivastava, H.K. Taylor, M.R. Hale, D.E. Hardt, L. Anand, J.

Micromech. Microeng., 19 (2009) 115030.

[40] Y. Saotome, S. Miwa, T. Zhang, A. Inoue, J. Mater. Process. Technol., 113 (2001) 64-69.

[41] J. Schroers, Q. Pham, A. Desai, J. Microelectromech. Syst., 16 (2007) 240-247.

[42] S. Mukherjee, M. Carmo, G. Kumar, R.C. Sekol, A.D. Taylor, J. Schroers, Electrochim. Acta, 74 (2012) 145-150.

[43] N. Clavaguera, M.T. Clavaguera-Mora, Mater. Sci. Eng., A, 179-180, Part 1 (1994) 288-292.

[44] A. Masuhr, T.A. Waniuk, R. Busch, W.L. Johnson, Phys. Rev. Lett., 82 (1999) 2290-

2293. 